\title{
Valved versus nonvalved cannula small-gauge pars plana vitrectomy for repair of retinal detachments with Grade C proliferative vitreoretinopathy
}

This article was published in the following Dove Press journal:

Clinical Ophthalmology

30 May 2016

Number of times this article has been viewed

\section{Patrick Oellers \\ Sandra Stinnett \\ Paul Hahn}

Duke Eye Center, Duke University School of Medicine, Durham, NC, USA
Purpose: Valved cannulas are a recent addition to small-gauge pars plana vitrectomy (PPV) and provide stable intraocular fluidics. The goal of this study was to compare outcomes and postoperative complication rates of valved vs nonvalved cannula small-gauge PPV for repair of retinal detachments (RDs) complicated by Grade C proliferative vitreoretinopathy (PVR).

Methods: A retrospective chart review of 364 consecutive eyes with either valved or nonvalved cannula PPV for RD repair was performed. The primary outcomes were single surgery and final anatomic success and change in best-corrected visual acuity for repair of RDs complicated by Grade C PVR.

Results: We identified 36 eyes in the valved group and 31 eyes in the nonvalved group with Grade C PVR RD. The single surgery success was $83 \%$ vs $77 \%(P=0.555)$ and the final anatomic success was $94 \%$ vs $87 \%$ ( $P=0.404)$ in the valved vs nonvalved eyes, respectively. The mean final visual acuity gain was -0.36 logarithm of the minimum angle of resolution (logMAR; approximate Early Treatment Diabetes Retinopathy Study [ETDRS] score $=17$ letters) in valved eyes vs $-0.33 \log$ MAR (approximate ETDRS score $=16$ letters) in nonvalved eyes $(P=0.81)$. Postoperative complication rates including postoperative day 1 hypotony, hypertony, and anterior chamber fibrin formation; postoperative retention of intraocular or subretinal perfluorocarbon liquid; and subsequent epiretinal membrane peel were not statistically different between groups. Conclusion: Valved cannula PPV yields equivalent visual acuity and anatomic outcomes without increased postoperative complication rates compared to traditional nonvalved cannula PPV for Grade C PVR-associated RD repair.

Keywords: 23 gauge, 25 gauge, PVR, RD, chronic, single surgery success, final anatomic success

\section{Introduction}

Small-gauge pars plana vitrectomy (PPV) systems have gained wide acceptance in vitreoretinal surgery due to their potential for reduced inflammation and rapid visual recovery. ${ }^{1}$ Recently, valved cannulas have been added to the vitreoretinal surgery armamentarium. They alleviate the need for cannula plugs during instrument exchange and minimize egress of fluid through cannulas during surgery. These advantages allow stable intraocular fluidics and improved dynamic control of intraocular pressure (IOP).

Proliferative vitreoretinopathy (PVR) is the most common etiology for recurrent retinal detachment (RD). ${ }^{2}$ The pathophysiology leading to PVR formation is not fully understood but thought to be at least partially inflammation mediated in a process
Correspondence: Paul Hahn

Duke Eye Center, Duke University

School of Medicine, DUMC Box 3802,

Durham, NC 277I0, USA

Tel+l919684563।

Email paulhahn@gmail.com 
analogous to excessive wound healing, driven by migrating and proliferating retinal pigment epithelium (RPE), glial cells, and bone marrow-derived inflammatory cells. ${ }^{3,4}$ Clinically, PVR is currently classified into Grades $\mathrm{A}-\mathrm{C}$, with Grade $\mathrm{C}$ being the most severe form manifested by preretinal and/or subretinal membranes. ${ }^{5}$ RD complicated by Grade C PVR poses a significant surgical challenge. The optimal surgical approach for Grade C PVR, such as use of an adjuvant scleral buckle (SB), inferior retinectomy, choice of tamponade, and vitrectomy gauge, remains controversial. ${ }^{2,6}$ Limited studies demonstrate encouraging surgical success rates when small-gauge vitrectomy systems are employed in the repair of RD with Grade C PVR..$^{7-10}$

To our knowledge, no studies in the literature have specifically evaluated the use of valved cannulas for RD repair complicated by PVR. The altered intraocular fluidics associated with valved cannulas may affect surgical outcomes. It is possible that there is decreased washout of debris and inflammatory products in eyes operated with valved cannulas that may lead to an increased rate of PVR and surgical failures. Alternatively, the diminished intraocular fluid currents associated with valved cannula use may cause decreased liberation of RPE cells, resulting in lower rates of induced PVR and improved surgical outcomes.

In this study, we retrospectively reviewed outcomes and complication rates of valved vs nonvalved cannula PPV for RD repair complicated by Grade C PVR at a single academic institution and found comparable functional and anatomic results as well as complication rates.

\section{Methods}

The study protocol was approved by the Institutional Review Board of the Duke University School of Medicine. We performed a retrospective chart review of eyes that underwent small-gauge (23 or 25 gauge) PPV with valved vs nonvalved cannulas for RD repair complicated by Grade C PVR. The clinical database tool Duke Enterprise Data Unified Content Explorer was used to search for Current Procedural Terminology codes 67108 and 67113, which are associated with vitrectomy for repair of RD. ${ }^{11}$ The Duke vitreoretinal service transitioned to valved cannulas in May 2012 and started exclusive use of valved cannulas in July 2012. The valved group consisted of valved cannula PPV between July 1, 2012 and January 31, 2013; the nonvalved group consisted of nonvalved cannula PPV between July 1, 2011 and January 31, 2012. Charts were reviewed to identify eyes with RDs complicated by documented Grade C PVR that were repaired with small-gauge PPV and use of temporary perfluorocarbon liquid (perfluoro-n-octane [PFO]).
The exclusion criteria included use of 20 -gauge vitrectomy, no PPV (eg, SB only), diagnosis other than RD (vitreous hemorrhage, epiretinal membrane [ERM], etc), traumatic RD or open globe, no use of PFO during PPV, abortion of the surgery from anesthesia-related complications, and postoperative follow-up $<3$ weeks.

Multiple surgeons performed standard three-port PPV using valved or nonvalved cannulas with an Alcon Constellation vitrectomy system (Alcon Laboratories, Inc., Forth Worth, TX, USA). PFO was used temporarily to flatten and stabilize the retina during PVR membrane peeling and/or to drain subretinal fluid. Based on individual discretion of the surgeon, adjuvant SB was placed, relaxing retinectomy was performed, and silicone oil, octafluoropropane gas $\left(\mathrm{C}_{3} \mathrm{~F}_{8}\right)$, or sulfur hexafluoride gas $\left(\mathrm{SF}_{6}\right)$ tamponade was utilized. For silicone oil fill, automated viscous fluid control injection was utilized in both valved and nonvalved cannula cases. For valved cannulas, either a chimney or a second instrument to displace one of the valve leaflets was used to vent the system, whereas for nonvalved cases, the cannula was left open to vent the system. PFO injection was performed slowly with a single bore cannula, and injection was temporarily halted in the case of optic nerve compromise until reperfusion was noted in both valved and nonvalved cannulas; the infusion line allowed retrograde fluid flow to alleviate the increased pressure induced by PFO injection.

Charts were analyzed for baseline demographics and preoperative characteristics (lens status, macula on vs off RD, recurrent $\mathrm{RD}$ [ie, unsuccessful prior $\mathrm{RD}$ repair] in the presenting eye, previous placement of SB) and type of surgery (gauge, adjuvant $\mathrm{SB}$, relaxing retinectomy, and tamponade).

The primary outcomes included best-corrected visual acuity (BCVA) change as well as rate of anatomic reattachment including single surgery success (retina attached at the final follow-up after single operation) and final anatomic success (retina attached at the final follow-up). Secondary outcomes included complication rates, including PFO-related complications, postoperative day 1 hypotony, hypertony, and rate of anterior chamber fibrin formation as well as rate of subsequent ERM peel after RD repair.

\section{Statistical analysis}

Visual acuity was converted to logarithm of the minimum angle of resolution $(\log M A R)$. To facilitate clinical interpretation of results, logMAR units were also reported in their Snellen equivalents. Visual improvement was converted to approximate Early Treatment Diabetes Retinopathy Study (ETDRS) letter improvement scores. ${ }^{12}$ Statistical differences were assessed by either the Fisher's exact test or Wilcoxon 
rank sum test. A $P$-value $<0.05$ was considered statistically significant.

\section{Results}

\section{Baseline data}

We reviewed 364 charts (196 in the valved group and 168 in the nonvalved group), of which 201 eyes were excluded based on prespecified criteria (valved cannula group: no PFO [ $n=38]$, insufficient follow-up [ $n=26]$, diagnosis other than RD [n=20], 20-gauge PPV [n=5], and traumatic RD [n=3]; nonvalved cannula group: 20-gauge PPV [ $n=34]$, no PFO [ $n=29]$, insufficient follow-up [ $n=23]$, diagnosis other than RD [n=18], no PPV [n=4], and surgery aborted because of anesthesia complications $[n=1])$. Of the remaining 163 eyes, 67 eyes were documented to have preoperative Grade C PVR. There were 36 eyes in the valved group and 31 eyes in the nonvalved group. Baseline data of both groups are displayed in Table 1. No significant demographic or preoperative characteristic differences existed between the groups. In the majority of eyes, the RD was macula off ( $83 \%$ in valved eyes vs $81 \%$ in nonvalved eyes, $P=1.000$ ) and recurrent $(67 \%$ in valved eyes vs $71 \%$ in nonvalved eyes, $P=0.795)$. The mean preoperative BCVA was $1.83 \log \mathrm{MAR}$ (Snellen equivalent $=20 / 1,352$ ) in the valved group vs 2.06 $\log$ MAR (Snellen equivalent $=20 / 2,296$ ) in the nonvalved group $(P=0.127)$.

\section{Surgical strategies}

No significant differences were present in surgical techniques and approaches (Table 2). The majority of eyes underwent 23 -gauge PPV ( $86 \%$ in the valved group vs $94 \%$ in the nonvalved group, $P=0.437)$, and the remaining minority eyes underwent 25-gauge PPV. Adjuvant SB was placed in 61\% of the valved eyes vs $58 \%$ of the nonvalved eyes $(P=0.809)$. Relaxing retinectomy was performed in 50\% vs 39\% in the valved and nonvalved groups, respectively $(P=0.461)$. All eyes received temporary PFO to drain subretinal fluid and/ or flatten and stabilize the retina during PVR membrane peeling as per the study inclusion criteria. In both groups, the most common tamponade was silicone oil $(72 \%$ in valved eyes vs $68 \%$ in nonvalved eyes, $P=1.000$ ) followed by $\mathrm{C}_{3} \mathrm{~F}_{8}$ ( $28 \%$ in valved eyes vs $32 \%$ in nonvalved eyes, $P=0.791$ ). $\mathrm{SF}_{6}$ was not used for tamponade in any of these Grade $\mathrm{C}$ PVR RD repairs.

\section{Functional outcomes}

The visual acuity outcomes are indicated in Table 3 . The final mean BCVA in the valved group was $1.47 \log$ MAR (Snellen equivalent 20/590) vs 1.74 logMAR (Snellen equivalent $20 / 1,099)$ in the nonvalved group $(P=0.124)$. Compared to baseline preoperative BCVA, the mean logMAR improvement at the final follow-up visit was -0.36 in the valved group and -0.33 in the nonvalved group $(P=0.824)$. The corresponding approximate ETDRS letter improvement score was +17 in the valved group vs +16 in the nonvalved group.

\section{Anatomic outcomes}

No statistically significant differences between the valved and nonvalved groups were found in anatomic outcomes (Table 3 ). The single surgery success was $83 \%$ vs $77 \%$ $(P=0.555)$ and the final anatomic success was $94 \%$ vs $87 \%$ $(P=0.404)$ in the valved vs nonvalved groups, respectively. The decision to observe and not to operate on detached

Table I Baseline demographic and preoperative characteristics

\begin{tabular}{|c|c|c|c|}
\hline Variable & Valved $(n=36)$ & Nonvalved $(n=31)$ & $P$-value \\
\hline Age, mean years (SD) & $58.70(\mid 8.7 I)$ & $52.07(19.53)$ & $0.119 *$ \\
\hline Male, n (\%) & $28(78)$ & $21(68)$ & $0.414^{* *}$ \\
\hline Right eye, n (\%) & $18(50)$ & $15(48)$ & $1.000 * *$ \\
\hline \multicolumn{4}{|l|}{ Lens } \\
\hline Pseudophakia, n (\%) & $22(6 \mathrm{I})$ & $15(48)$ & \\
\hline Phakia, n (\%) & II (3I) & $14(45)$ & \\
\hline Aphakia, n (\%) & $3(8)$ & $2(6)$ & $0.516 * *$ \\
\hline Macula off, $n(\%)$ & $30(83)$ & $25(8 I)$ & $1.000^{* *}$ \\
\hline Previous history of RD in the presenting eye, $n$ (\%) & $24(67)$ & $22(7 I)$ & $0.795 * *$ \\
\hline Previous placement of scleral buckle in the presenting eye, $n(\%)$ & $12(33)$ & $7(23)$ & 0.419 \\
\hline Grade C PVR, n (\%) & $36(100)$ & $31(100)$ & \\
\hline \multicolumn{4}{|l|}{ Preoperative BCVA } \\
\hline $\log M A R$, mean $(S D)$ & $\mathrm{I} .83(0.84)^{* * *}$ & $2.06(0.83)$ & $0.127^{*}$ \\
\hline Snellen equivalent & $20 / 1,352$ & $20 / 2,296$ & \\
\hline
\end{tabular}

Notes: *P-value based on Wilcoxon rank sum test of difference between medians. **P-value based on Fisher's exact test of difference between proportions. ***Preoperative BCVA only available in 35 of 36 eyes in the valved group.

Abbreviations: RD, retinal detachment; PVR, proliferative vitreoretinopathy; BCVA, best-corrected visual acuity; logMAR, logarithm of the minimum angle of resolution. 
Table 2 Surgical strategies

\begin{tabular}{|c|c|c|c|}
\hline Variable & $\begin{array}{l}\text { Valved } \\
(n=36)\end{array}$ & $\begin{array}{l}\text { Nonvalved } \\
(n=3 I)\end{array}$ & $P$-value* \\
\hline \multicolumn{4}{|l|}{ Type of small-gauge vitrectomy } \\
\hline 23 gauge, $n(\%)$ & $31(86)$ & $2(94)$ & \multirow{2}{*}{0.437} \\
\hline 25 gauge, $n(\%)$ & $5(14)$ & $2(6)$ & \\
\hline Adjuvant SB, n (\%) & $22(6 I)$ & $18(58)$ & 0.809 \\
\hline Relaxing retinectomy, n (\%) & $18(50)$ & $12(39)$ & $0.46 \mathrm{I}$ \\
\hline PFO used, n (\%) & $36(100)$ & $31(100)$ & 1.000 \\
\hline $\mathrm{C}_{3} \mathrm{~F}_{8}$ tamponade, $\mathrm{n}(\%)$ & $10(28)$ & $10(32)$ & 0.791 \\
\hline Silicone oil tamponade, $\mathrm{n}(\%)$ & $26(72)$ & $21(68)$ & 1.000 \\
\hline
\end{tabular}

Note: ${ }^{*} P$-value based on Fisher's exact test of difference between proportions.

Abbreviations: SB, scleral buckle; PFO, perfluoro-n-octane.

retinas was due to poor visual prognosis $(n=1$ in the valved group, $n=3$ in the nonvalved group) and patient preference ( $n=1$ in the valved group, $n=1$ in the nonvalved group). PVR was the most common etiology for recurrent $\mathrm{RD}$ in both groups $(83 \%$ in the valved eyes vs $71 \%$ in the nonvalved eyes, $P=1.000)$. Alternative etiologies were recurrent RD without documented hole, break, or PVR under silicone oil ( $n=1$, valved group; $n=1$, nonvalved group) and recurrent $R D$ without documented hole, break, or PVR 1 month following silicone oil removal ( $\mathrm{n}=1$, nonvalved group).

\section{Complications}

No significant differences existed in postoperative complication rates (Table 4). Intraocular retained $\mathrm{PFO}$ was reported in $6 \%$ vs $10 \%$ of the valved and nonvalved groups $(P=0.656)$, which was removed surgically in $100 \%(n=3)$ of the valved group and $0 \%$ of the nonvalved group $(P=0.100)$. Subretinal retained $\mathrm{PFO}$ was detected in $11 \%$ of the valved group and $3 \%$ of the nonvalved group $(\mathrm{p}=0.363)$ and was observed without surgical removal in all cases. There were no significant differences in postoperative day 1 anterior chamber fibrin reaction, postoperative day 1 hypotony or hypertony, as well as subsequent ERM peeling between the groups.
No cases of iatrogenic retinal breaks due to retinal incarceration at the cannula site were reported in either group.

\section{Discussion}

While small-gauge systems have been increasingly adopted in the management of a variety of vitreoretinal conditions, only limited knowledge exists regarding their impact on outcomes and complications of complex pathologic conditions such as Grade C PVR-associated RD. To our knowledge, the present study is the only series specifically investigating valved cannulas for the repair of RD complicated by Grade C PVR. We show statistically equivalent visual improvement, single surgery success, final anatomic success, as well as complication rates with valved vs nonvalved PPV.

The study population consists of eyes with complex RD associated with Grade C PVR presenting to a tertiary referral center. There is a correspondingly high proportion of recurrent RDs and macula off detachments associated with poor preoperative vision and poor anatomic and functional prognosis. In this series, repair with valved cannulas was performed 1 calendar year following nonvalved cannulas, but both groups had comparable baseline demographics and preoperative characteristics.

Anatomic outcomes of this study, with single surgery success of $83 \%$ vs $77 \%$ and final anatomic success of $94 \%$ vs $83 \%$ in valved vs nonvalved eyes, respectively, compare favorably to the literature of traditional 20-gauge PPV as well as the available data on small-gauge PPV for Grade C PVR-associated $R D$ repair. ${ }^{7,10,13-16}$ Despite anatomic success and overall visual improvement in both groups, functional data demonstrate less encouraging results. Sixty-six percent of the valved eyes and $84 \%$ of the nonvalved eyes remained with 20/200 or worse BCVA at the final follow-up, which is consistent with the previously reported studies on eyes with PVR-associated RD. ${ }^{13,15}$

Table 3 Outcomes

\begin{tabular}{llll}
\hline Variable & Valved $(\mathbf{n}=\mathbf{3 6})$ & Nonvalved $(\mathbf{n}=\mathbf{3} \mathbf{I})$ & P-value \\
\hline Final BCVA $\leq 20 / 40, \mathrm{n}(\%)$ & $2(6)$ & $\mathrm{I}(3)$ & $\mathrm{I}$ \\
Final BCVA $\geq 20 / 200, \mathrm{n}(\%)$ & $23(66)$ & $26(84)$ & $0.157^{*}$ \\
Final logMAR BCVA, mean (SD) & $1.47(0.8 \mathrm{I})$ & $1.74(0.88)$ & $0.124^{* *}$ \\
Snellen equivalent & $20 / 590$ & $20 / 1,099$ & \\
Final logMAR change in BCVA, mean (SD) & $-0.36(1.00)$ & $-0.33(0.94)$ & $0.812^{* *}$ \\
Approximate ETDRS improvement score & +17 & +16 & \\
Single surgery success, $\mathrm{n}(\%)$ & $30(83)$ & $24(77)$ & $0.555^{*}$ \\
Final anatomical success, $\mathrm{n}(\%)$ & $34(94)$ & $27(87)$ & $0.404^{*}$ \\
Follow-up days, mean (SD) & $345.8(204.0)$ & $564.5(333.5)$ & $0.004^{* *}$ \\
\hline
\end{tabular}

Notes: $* P$-value based on Fisher's exact test of difference between proportions. $* * P$-value based on Wilcoxon rank sum test of difference between medians. Abbreviations: BCVA, best-corrected visual acuity; logMAR, logarithm of the minimum angle of resolution; ETDRS, Early Treatment Diabetes Retinopathy Study. 
Table 4 Complications

\begin{tabular}{|c|c|c|c|}
\hline Variable & $\begin{array}{l}\text { Valved } \\
(n=36)\end{array}$ & $\begin{array}{l}\text { Nonvalved } \\
(n=31)\end{array}$ & $P$-value \\
\hline PODI anterior chamber fibrin, $\mathrm{n}(\%)$ & II (3I) & $6(2 I)$ & 0.402 \\
\hline PODI IOP < 7 mmHg, n (\%) & $4(\mathrm{II})$ & $3(10)$ & 1.000 \\
\hline PODI IOP > 26 mmHg, n (\%) & $5(14)$ & $3(10)$ & 0.719 \\
\hline Intraocular retained PFO, n (\%) & $2(6)$ & $3(10)$ & 0.656 \\
\hline Subsequent surgical removal, n (\%) & $2(100)$ & $0(0)$ & 0.100 \\
\hline Subretinal retained PFO, n (\%) & $4(11)$ & I (3) & 0.363 \\
\hline Subsequent surgical removal, $\mathrm{n}(\%)$ & $0(0)$ & $0(0)$ & 1.000 \\
\hline ERM peel after RD repair, n (\%) & $2(6)$ & I (3) & 1.000 \\
\hline
\end{tabular}

Note: $P$-value based on Fisher's exact test of difference between proportions. Abbreviations: PODI, postoperative day I; IOP, intraocular pressure; PFO, perfluoro-n-octane; ERM, epiretinal membrane; RD, retinal detachment.

In a previous study, we did not identify differences in outcomes or complications with valved versus nonvalved cannulas for a heterogeneous RD population of simple and complex detachments. ${ }^{17}$ However, we hypothesized that altered intraocular fluidics associated with valved cannulas may modulate the outcome of PVR-associated complex $\mathrm{RD}$ repair. Decreased intraocular fluid currents with valved cannulas may result in reduced RPE seeding and less recurrent PVR. Alternatively, the reduced egress of fluid through valved cannulas may hinder washout of inflammatory proteins, debris, and cells, resulting in higher rates of recurrent PVR. However, for both functional and anatomic outcomes, the study found no measurable difference between valved and nonvalved cannulas. There were trends toward improved outcomes with valved cannulas in this study, and it is possible that this study was not adequately powered to detect this difference.

Iatrogenic retinal breaks may be a complication of vitrectomy, and reported incidences range from $1.6 \%$ to $6.2 \% \cdot{ }^{18-20}$ One etiology for iatrogenic retinal breaks is vitreous incarceration, which can occur due to vitreous attraction to open cannulas. ${ }^{21-23}$ The stable fluidics of valved cannulas offers a potential for decreased attraction of vitreous incarceration into the cannulas, which has been shown experimentally in the eyes of rabbit. ${ }^{24}$ In our series, no case of vitreous incarceration at the cannula site was reported in either group, but it is possible that a larger series will elucidate a difference.

The improved stability of intraocular fluidics with valved cannulas requires adjustments to certain surgical approaches. Owing to the closed system fluidics of valved cannulas, venting must be performed when injecting additional volume such as silicone oil or PFO. A chimney or a second instrument to displace one of the valve leaflets was used to vent the eye when inserting silicone oil with valved cannulas, whereas with nonvalved cannulas, a cannula was simply left open. Typically, slow injection of PFO is sufficient to avoid significant IOP rise with both valved and nonvalved cannulas, as the infusion line can allow retrograde flow of fluid (but not air), but if optic nerve perfusion was compromised, temporary pausing of the injection was performed. Dual-bore injection cannulas may also be used to avoid IOP rise secondary to PFO injection, ${ }^{25}$ but were not used during the time of this study. While the methods of administration of these agents were similar between valved and nonvalved cannula groups, differences in fluidics may result in important differences in outcomes or complications that were undetected by this study.

There are several other limitations in this study. This is a retrospective study whose data are limited by what was recorded in the medical record. There was a significantly longer follow-up time in the nonvalved group, whose study period was 1 year prior to the valved group, which may bias the nonvalved group toward worse anatomic outcomes. The study times of the two groups were temporally distinct, and although the baseline characteristics and surgical approaches of the two groups were not different, there may have been differences in variables that were not analyzed. On the other hand, these distinct study periods may also reduce selection bias from surgeon preference or based on preoperative characteristics, as choice of valved vs nonvalved cannula use was not at the surgeon's discretion but rather a result of an institutional shift from the use of nonvalved to valved cannulas.

\section{Conclusion}

This is the first series that specifically evaluated valved vs nonvalved PPV for Grade C PVR-associated RD. Appropriate rates of retinal reattachment were realized both with valved and nonvalved cannulas. No differences in functional or anatomic outcomes as well as complication rates were identified between the PPV of valved and nonvalved cannulas. In our opinion, advantages of valved cannulas, including minimal egress of fluid during instrument exchange and associated stable intraocular fluidics, translate into easier and more controlled surgery with equivalent anatomic outcomes in complex Grade C PVR RD without measurable increase in complication rates. Future studies should focus on improving functional visual results in Grade C PVR-associated RD.

\section{Acknowledgment}

The authors have not received any grant support for this article nor have any proprietary interest in the data presented. 


\section{Disclosure}

The authors report no conflicts of interest in this work.

\section{References}

1. Thompson JT. Advantages and limitations of small gauge vitrectomy. Surv Ophthalmol. 2011;56(2):162-172.

2. Khan MA, Brady CJ, Kaiser RS. Clinical management of proliferative vitreoretinopathy: an update. Retina. 2015;35(2):165-175.

3. Garweg JG, Tappeiner C, Halberstadt M. Pathophysiology of proliferative vitreoretinopathy in retinal detachment. Surv Ophthalmol. 2013;58(4): 321-329.

4. Pastor JC, Rojas J, Pastor-Idoate S, Di Lauro S, Gonzalez-Buendia L, Delgado-Tirado S. Proliferative vitreoretinopathy: a new concept of disease pathogenesis and practical consequences. Prog Retin Eye Res. 2016; $51: 125-155$.

5. Machemer R, Aaberg TM, Freeman HM, Irvine AR, Lean JS, Michels RM. An updated classification of retinal detachment with proliferative vitreoretinopathy. Am J Ophthalmol. 1991;112(2):159-165.

6. Schwartz SG, Flynn HW Jr, Lee WH, Wang X. Tamponade in surgery for retinal detachment associated with proliferative vitreoretinopathy. Cochrane Database Syst Rev. 2014;2:CD006126.

7. Erakgun T, Egrilmez S. Surgical outcomes of transconjunctival sutureless 23 -gauge vitrectomy with silicone oil injection. Indian J Ophthalmol. 2009;57(2):105-109.

8. Shah CP, Ho AC, Regillo CD, Fineman MS, Vander JF, Brown GC. Short-term outcomes of 25-gauge vitrectomy with silicone oil for repair of complicated retinal detachment. Retina. 2008;28(5):723-728.

9. Riemann CD, Miller DM, Foster RE, Petersen MR. Outcomes of transconjunctival sutureless 25 -gauge vitrectomy with silicone oil infusion. Retina. 2007;27(3):296-303.

10. Storey P, Alshareef R, Khuthaila M, et al. Pars plana vitrectomy and scleral buckle versus pars plana vitrectomy alone for patients with rhegmatogenous retinal detachment at high risk for proliferative vitreoretinopathy. Retina. 2014;34(10):1945-1951.

11. Roth C, Rusincovitch SA, Horvath MM, et al. DEDUCE clinical text: an ontology-based module to support self-service clinical notes exploration and cohort development. AMIA Jt Summits Transl Sci Proc. 2013; 2013:227.

12. Gregori NZ, Feuer W, Rosenfeld PJ. Novel method for analyzing snellen visual acuity measurements. Retina. 2010;30(7):1046-1050.
13. Vitrectomy with silicone oil or sulfur hexafluoride gas in eyes with severe proliferative vitreoretinopathy: results of a randomized clinical trial. Silicone Study Report 1. Arch Ophthalmol. 1992;110(6):770-779.

14. Joussen AM, Rizzo S, Kirchhof B, et al. Heavy silicone oil versus standard silicone oil in as vitreous tamponade in inferior PVR (HSO Study): interim analysis. Acta Ophthalmol. 2011;89(6):e483-e489.

15. Scott IU, Flynn HW Jr, Murray TG, Feuer WJ; Perfluoron study group. Outcomes of surgery for retinal detachment associated with proliferative vitreoretinopathy using perfluoro-n-octane: a multicenter study. Am J Ophthalmol. 2003;136(3):454-463.

16. Adelman RA, Parnes AJ, Sipperley JO, Ducournau D; European VitreoRetinal Society (EVRS) Retinal Detachment Study Group. Strategy for the management of complex retinal detachments: the European vitreoretinal society retinal detachment study report 2. Ophthalmology. 2013; 120(9):1809-1813.

17. Oellers P, Stinnett S, Mruthyunjaya P, Hahn P. Small-gauge valved versus nonvalved cannula pars plana vitrectomy for retinal detachment repair. Retina. 2016;36(4):744-749.

18. Mura M, Barca F, Dell'Omo R, Nasini F, Peiretti E. Iatrogenic retinal breaks in ultrahigh-speed 25-gauge vitrectomy: a prospective study of elective cases. Br J Ophthalmol. Epub 2015 Dec 23.

19. Cha DM, Woo SJ, Park KH, Chung H. Intraoperative iatrogenic peripheral retinal break in 23-gauge transconjunctival sutureless vitrectomy versus 20-gauge conventional vitrectomy. Graefes Arch Clin Exp Ophthalmol. 2013;251(6):1469-1474.

20. Wimpissinger B, Binder S. Entry-site-related retinal detachment after pars plana vitrectomy. Acta Ophthalmol Scand. 2007;85(7):782-785.

21. Tan HS, Mura M, de Smet MD. Iatrogenic retinal breaks in 25-gauge macular surgery. Am J Ophthalmol. 2009;148(3):427-430.

22. Gosse E, Newsom R, Lochhead J. The incidence and distribution of iatrogenic retinal tears in 20-gauge and 23-gauge vitrectomy. Eye. 2012; 26(1):140-143.

23. Ehrlich R, Goh YW, Ahmad N, Polkinghorne P. Retinal breaks in small-gauge pars plana vitrectomy. Am J Ophthalmol. 2012;153(5): 868-872.

24. Abulon DJ, Charles M, Charles DE. Globe stability during simulated vitrectomy with valved and non-valved trocar cannulas. Clin Ophthalmol. 2015;9:1745-1752.

25. Toygar O, Berrocal MH, Charles M, Riemann CD. Next-generation dual-bore cannula for injection of vital dyes and heavy liquids during pars plana vitrectomy. Retina. 2016;36(3):582-587.
Clinical Ophthalmology

\section{Publish your work in this journal}

Clinical Ophthalmology is an international, peer-reviewed journal covering all subspecialties within ophthalmology. Key topics include: Optometry; Visual science; Pharmacology and drug therapy in eye diseases; Basic Sciences; Primary and Secondary eye care; Patient Safety and Quality of Care Improvements. This journal is indexed on Submit your manuscript here: http://www.dovepress.com/clinical-ophthalmology-journal

\section{Dovepress}

PubMed Central and CAS, and is the official journal of The Society of Clinical Ophthalmology (SCO). The manuscript management system is completely online and includes a very quick and fair peer-review system, which is all easy to use. Visit http://www.dovepress.com/ testimonials.php to read real quotes from published authors. 